\title{
SCHUR-CONVEXITY FOR A CLASS OF SYMMETRIC FUNCTION AND ITS APPLICATIONS
}

\author{
KAIZHONG GUAN AND JiANHUA SHEN
}

Abstract. In this paper, we investigate the symmetric function

$$
\prod_{n}^{r}(f)=\prod_{n}^{r}(f(x))=\left(\prod_{1 \leqslant i_{1}<i_{2}<\ldots<i_{r} \leqslant n} f\left(\frac{1}{r} \sum_{j=1}^{r} x_{i_{j}}\right)\right)^{\frac{1}{\left(\begin{array}{c}
n \\
r
\end{array}\right)}},
$$

where $f(x)$ is a positive function on an interval $I$. Some analytic inequalities, including "Ky Fan" type inequalities, are established by use of the theory of majorization. An open problem is also solved partly.

Mathematics subject classification (2000): 05E05, 26D20.

Key words and phrases: weakly logarithmic convex (concave) function, symmetric function, theory of majorization, Ky Fan inequality.

\section{REFERENCES}

[1] G. Klambauer, Problems and Propositions in Analysis, Marcel Dekker, Inc., New York, 1979.

[2] Kunang Jichang, Applied Inequalities (3nd. Ed.), Shangdong Science and Technology Press, Jinan, 2004.

[3] KAIZHONG GUAN, Schur-convexity of the complete elementary symmetric function, J. of Inequalities and Applications (in press).

[4] X. P. PenG, Symmetric mean and its basic theorem, Hunan Mathematical messages, 3 (1991), 39-40.

[5] K. Z. GuAN, Weakly logarithmic convex function and its applications, Henyang Shizhuan Xuebao, 3 (1990), 49-56.

[6] A. W. MARShall, I. OlKIn, Inequalities: Theory of Majorization and Its Applications, Academic Press, 1979.

[7] K. Z. GUAN, A symmetric mean about weakly logarithmic convex function, J. of Hengyang Normal University, 3 (2001), 63-67.

[8] G. H. HARDY, J. E. LitTLEWOOD, AND D. PólYA, Some simple inequalities satisfied by convex functions, Messenger Math., 58 (1929), 145-152.

[9] A. Wayne Roberts and Dale E. Varberg, Convex Function, Academic Press, New York, San Francisco, London, 1973.

[10] D. S. Mitrinović, Analytic Inequalities, Springer-Verlag, New York, 1970.

[11] S. S. DRAGOMIR, Some refinements of Ky Fan's inequality, J. Math. Anal. Appl., 163 (1992), 317-321.

[12] G. H. HARdy, J. E. LitTlewood, AND D. Pólya, Inequalities (2nd. Ed.), Cambridge University Press, New York, 1952.

[13] J. PeČARIĆ, D. SVRTAN, New refinements of the Jensen inequalities based on samples with repetitions, J. Math. Anal. Appl., 222 (1998), 365-373.

[14] BOYING WANG, Foundations of Majorization Inequality, Beijing Normal University Press, Beijing, 1990.

[15] ]H. Alzer, The inequality of Ky Fan and related results, Acta. Appl. Math., 38 (1995), 305-354. 